\title{
APPLICATION OF THERMOGRAPHY TO ANALYZE THE EFFECTIVENESS OF ERGOMETER TRAINING
}

\author{
Jarosław Zubrzycki $i^{1 \Xi}$, Natalia Smidova², Magdalena Bajura ${ }^{3}$ \\ $1 \square$ Lublin University of Technology, Mechanical Engineering Faculty, Department of Biomedical Engineering, \\ 36 Nadbystrzycka Str., 20-618 Lublin, Poland, ORCID ID 0000-0002-7454-8090, ResearcherID B-2767-2016, \\ email: j.zubrzycki@pollub.pl \\ ${ }^{2}$ Technical University of Kosice, Faculty of Electrical Engineering of Information, Department of Physics, Park \\ Angelinum 9, 04001 Kosice; email: Natalia.Smidova@tuke.sk \\ ${ }^{2}$ Lublin University of Technology, Mechanical Engineering Faculty, Department of Biomedical Engineering, \\ master study student
}

Submitted: 2019-09-06 / Accepted: 2019-09-07 / Published: 2019-12-27

\begin{abstract}
The work determines the degree of thermographic suitability of the method of temperature measurement in people exercising on a rowing ergometer.

Thermography is gaining popularity in medical diagnostics by measuring the body temperature. Its main advantages are non-invasive, safe and comfortable for patients. It is widely used in the prevention of breast cancer and treatment of osteoarticular injuries. The basis for the use of thermography in medicine is the phenomenon of thermoregulation of living organisms and the emissive property of the skin, which is similar in value to a perfectly black body.

To achieve the set goal, 10 people were trained on the rowing ergometer. During the two series of measurements (before and immediately after), the focus was on two areas of the subjects' body: upper limbs and abdomen.

The thermographs obtained were analyzed taking into account the physical and physiological parameters of the players and their experience. The conclusions from them seemed to answer the thesis that the thermographic method is suitable for supporting players in planning and improving their training. It has also been shown that training on a rowing ergometer involves many muscle parties in which an increase in the released metabolic heat takes place.
\end{abstract}

KEYWORDS: thermography, body temperature distribution, rowing ergometer

\section{Introduction}

Thermography, also called thermovision, is a non-contact method of measuring surface temperature in real time. Due to its non-invasive nature and the lack of side effects associated with the research, this method is gaining increasing popularity in biomedical engineering and medicine. It is based on receiving infrared radiation that accompanies all physiological and pathological processes in living organisms. Thermography allows identification of inflammatory foci by characteristic temperature changes.

This identification can be made both in terms of value and their spatial distribution. The virtues of thermovision are used in almost all fields of medicine, such as cardiosurgery, oncology or dentistry. It also has a large share in the diagnosis of sports medicine and rehabilitation. Here, thermographs are used to assess the degree of involvement of given parts of the body in the movement performed and the effectiveness of the rehabilitation carried out. Data obtained from the 
thermographic study provide athletes with information on the effectiveness and symmetry of the trainings. It is also possible to estimate the likelihood of an injury. The information acquired thanks to thermographic research can form the basis for planning trainings and physical preparation of professional players.

\section{Physiological bases of thermal measurements}

The use of thermography in medical diagnostics would not be possible if the human body didn't naturally release heat. Already in ancient Greek times, Hippocrates, called the father of medicine, said that "if one part of the body is warmer or colder than others, it is who is affected by the disease". Currently, it is already known that under physiological conditions the body temperature is constant and every significant fluctuation is considered to be a disorder of the body's homeostasis, that is, the natural and stable internal conditions of the body. It is connected with the warmbloodedness of the homo sapiens and a number of mechanisms developed in the course of evolution, which keep the warm-bloodedness.

\subsection{The phenomenon and thermoregulation mechanism}

The temperature is assumed about $37^{\circ} \mathrm{C}$ for the proper human body with an acceptable fluctuation of the body's interior temperature on average from 0.5 to $0.7^{\circ} \mathrm{C}$, regardless of the prevailing environmental conditions. The so-called core heat characterizes the largest warmbloodedness in the human body, which include chest, abdomen, internal organs, blood and skull. On the other hand, areas more prone to temperature fluctuations are skin (the so-called curtain part) and limbs. In changing environmental conditions, warm-blooded organisms are equipped with a mechanism that allows them to maintain a relatively constant body temperature regardless of changes in ambient temperature or physical exercise. A thermoregulation mechanism controls the defense of the body against excess or deficiency of heat. This mechanism has its center located in the hypothalamus - a small part of the brain.

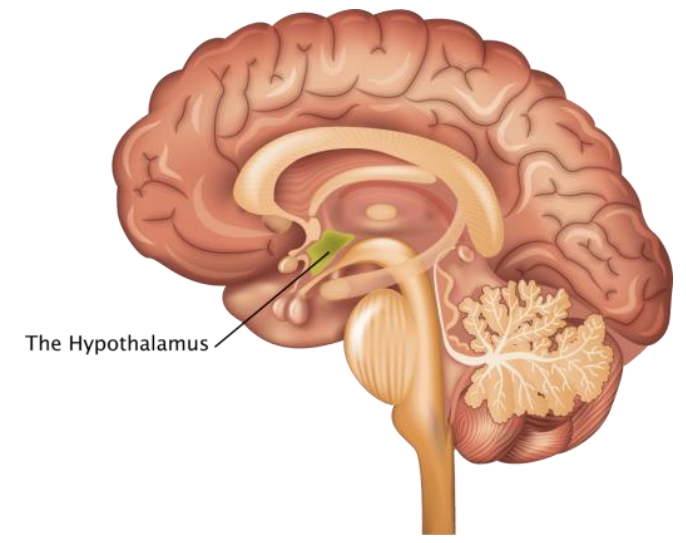

Fig. 1. Hypothalamus [1]

This is where thermosensitive neurons gather information about the current body temperature. However, before information about body temperature reaches the hypothalamus, it must be picked up by specialized receptors called thermoreceptors. In the human anatomy, the thermoreceptors are subjected to division into the cutaneous, brain and hypothalamus and reticular system of the brain stem (ARAS). Among skin thermoreceptors, several types can be distinguished depending on the range of temperatures to which they react. The first group are cold receptors that respond to temperatures in the range of $27-38^{\circ} \mathrm{C}$. The Krause final bodies that make up them are found primarily in the lamina propria of the mucous membranes and in the sub-dermal layer of the skin.

The second group, which responds to temperatures between $38-42^{\circ} \mathrm{C}$, called heat receptors. Ruffini body, are present in the proper skin, subcutaneous tissue as well as periosteal, and omiaxial 
build them. Often, thermoreceptors also include pain receptors (nocreceptors) that respond to temperatures of $10-15^{\circ} \mathrm{C}$ or above $45^{\circ} \mathrm{C}$. Often, thermoreceptors also include pain receptors (nocreceptors) that respond to temperatures of $10-15^{\circ} \mathrm{C}$ or above $45^{\circ} \mathrm{C}$.

Each information about temperature change received by the hypothalamus triggers a number of processes leading to elevated temperature (thermogenesis) or to its lowering. The autonomic nervous system plays a key role here. Its sympathetic and parasympathetic systems act antagonistically to each other, ensuring the leveling of unwanted jumps or drops in temperature. The processes that trigger are included in unconditional reflexes and occur mainly in the skin system, circulatory system, respiratory system and changes in the intensity of cell metabolism.

\subsection{Human skin as a perfect black body}

Human skin is a natural barrier separating the interior of the body from the external environment, which largely affects the maintenance of homeostasis. The thickness of the skin is different depending on the part of the body. However, it always consists of two layers: the epidermis and dermis.

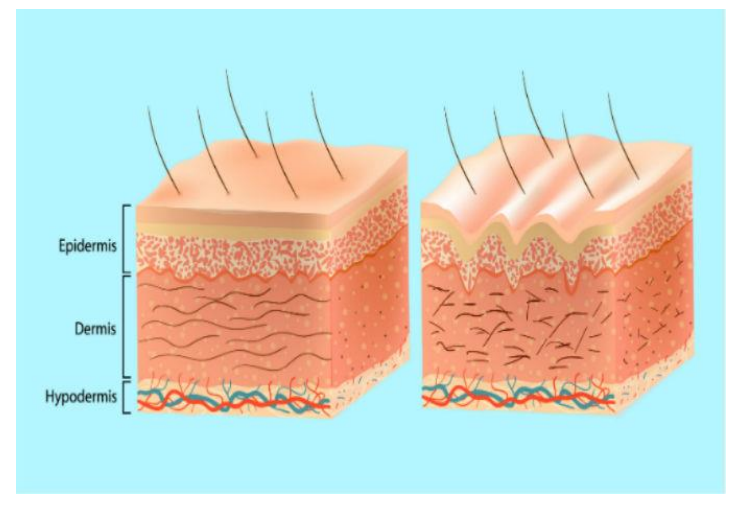

Fig. 2. Layer structure of the skin [2]

The skin has many functions, which is also equipped with many different properties. However, considering it in terms of its radiant properties, the distinctive physical property of the skin is its emissivity.

Research conducted, among others in the 1970's, it proved that human skin is a grey body with an emissivity value of 0.98 [3]. This value is very similar to the emissivity value of a perfect black body $(\varepsilon=1)$. This allows us to state that human skin is an excellent absorbent as well as an emitter of infrared radiation. Subsequent studies have shown that the human body emits radiation in the range from $2 \mu \mathrm{m}$ to as much as $15 \mu \mathrm{m}$. However, it achieves the maximum of its emittance at a wavelength of $9.36 \mu \mathrm{m}$. These facts have made the human body an ideal object for thermovision research.

\section{Physical basis of thermovision measurements}

Technologies are based on the laws of nature known to humanity. It can be said that every technology created is a practical use of physical, chemical or biological phenomena. It is no different with thermography, which is based on infrared radiation, also called thermal radiation. It is thanks to this phenomenon discovered in $\mathbf{1 8 0 0}$ by William Herschel that it is possible to observe the bodies for the heat they emit.

In every body whose temperature is higher than absolute zero (OK), there is a thermal arousal of matter-building particles such as ions, atoms and whole particles. This stimulation produces electromagnetic radiation, which in the quantum description is presented as a stream of photons that do not have a mass with the energy of a single photon dependent on its wavelength. 
Thanks to the Lousa de Brogile wave of the matter of the corpuscular-wave dualism of matter, each material object can be described as a set of particles or as a wave. It allows describing the dependence of wavelength (1) and photon energy (2).

$$
\lambda=\frac{c}{v}
$$

where:

c - speed of light in a vacuum

$v$ - photon frequency

$$
E=h \cdot v
$$

where:

h - Planck's constant

$v$ - photon frequency

At least one of these quantities is necessary to identify electromagnetic waves. The division of waves occurs due to the frequency ranges, wavelength or energy of a single quantum radiation. Such a division is called the spectrum of electromagnetic radiation or Maxwell's rainbow.

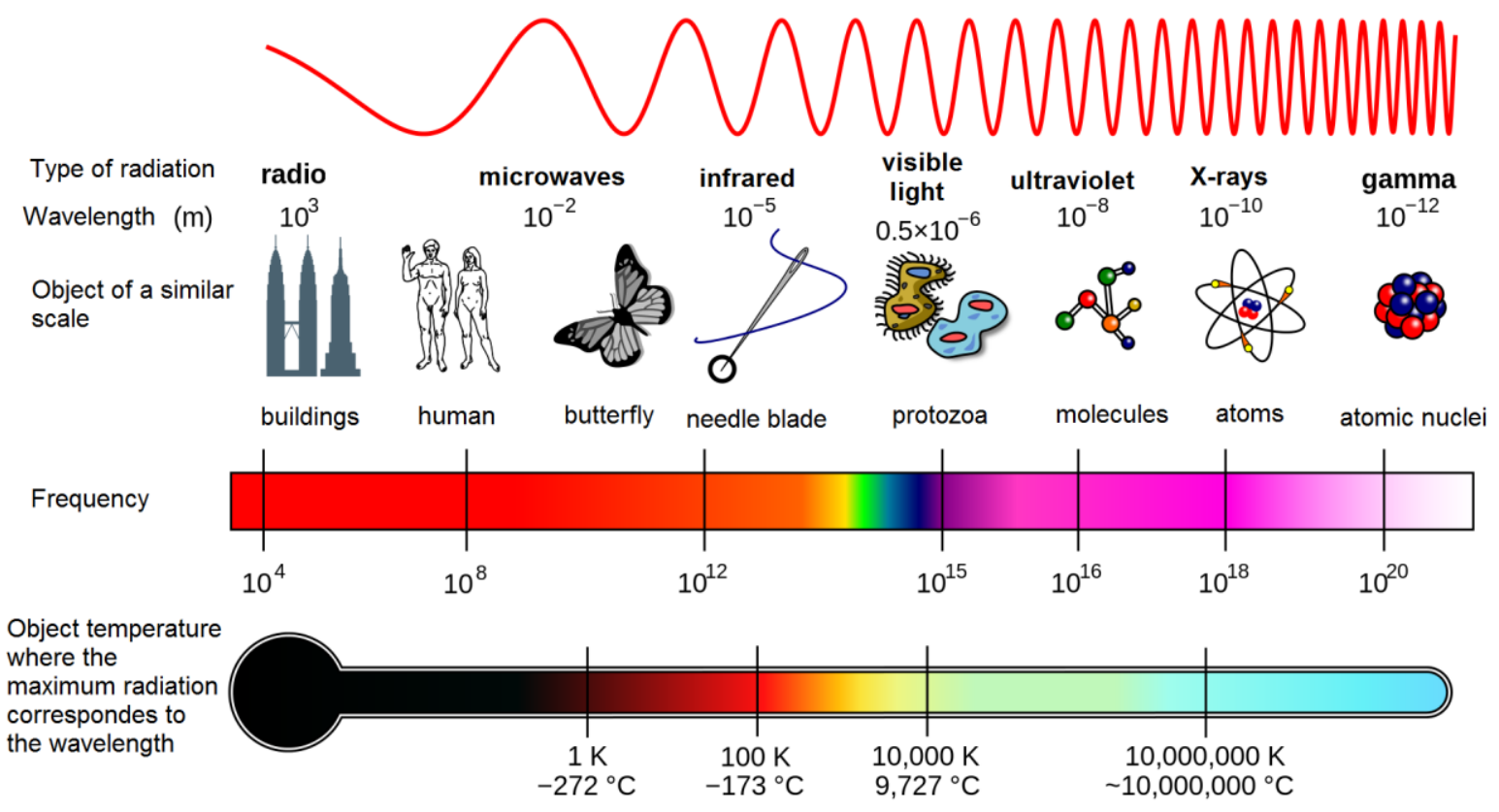

Fig. 3. Maxwell's rainbow

The most important waves from the point of view of thermography are infrared waves recorded by thermal imaging cameras. These are waves in the range from $300 \mathrm{GHz}$ to $400 \mathrm{THz}$ with wavelength from $1 \mathrm{~mm}$ to $780 \mathrm{~nm}$ and energy from $1.24 \mathrm{meV}$ to $1.6 \mathrm{eV}$.

\section{Thermal imaging cameras}

Thermal imaging cameras are devices that register infrared radiation. The signal recorded by them is processed and displayed on the screen of the camera or computer with which the camera connects using special software. Thermal imaging cameras can be divided depending on their spectral range. Most often for medium wave MWIR (range $3 \div 6 \mu \mathrm{m}$ ) and long-wave LWIR $(7 \div 14$ 
$\mu \mathrm{m})$. Thermovision measuring cameras (accurate measurement of temperature distribution) and observation cameras (accurate representation of the object, eg the scenery of the observed area, with only a qualitative assessment of the temperature distribution) are produced.

The thermal imaging camera is built from several basic components. They are a matrix of detectors that converts thermal radiation into an electrical signal and an optical system for the infrared range. There is also an electronics amplifying and transforming the signal received from the detector into the image displayed on the camera screen. Infrared detectors determine the limitations of observation and measuring infrared camera. These are the most technologically advanced camera components that act as transducers of the radiation energy to a different physical quantity that can be current, voltage or change of resistance.

Different types of detectors are used in thermal imaging cameras. There are several divisions. Single and matrix detectors differ in the number and arrangement of detectors. Matrix, called FPA (Focal Panel Array), consist of individual detectors, where each of them corresponds to one pixel, creating a matrix. The sizes of matrices are adjusted to the image display standards, so their most common dimensions are $320 \times 240,384 \times 288,640 \times 480,640 \times 512$ and $1280 \times 1024$ detectors. The minimum size of a single detector (pixel) for MWIR array matrices is currently about $12 \mu \mathrm{m}$ and for the LWIR range about $15 \mu \mathrm{m}$.

Currently, thermovision cameras use matrix-cooled detectors made of InSb, HgCdTe or QWIP detectors. However, in the recent years, the production of matrix non-cooled detectors has been developing very intensively, among which microbolometric detectors most frequently are used. They enable the recording of images in the long-wave infrared range $(8-14 \mu \mathrm{m})$ and work in the visible range for humans $(400-700 \mathrm{~nm})$. Their main advantages are the thermal sensitivity below $40 \mathrm{mK}$, small dimensions of sensitive elements (about $17 \mu \mathrm{m}$ ) and a large number of detectors in the matrix (eg 1280x1024). Microbolometric detectors contain several layers (Figure 4). The first layer is a dozen or several dozen $\mathrm{nm}$ absorbent. On it there is a thermally insulated silicon structure with a thickness of about $100 \mathrm{~nm}$ made in MEMS micromechanical technology. These detectors can work in a very wide spectral range and optical filters determine their operating ranges.

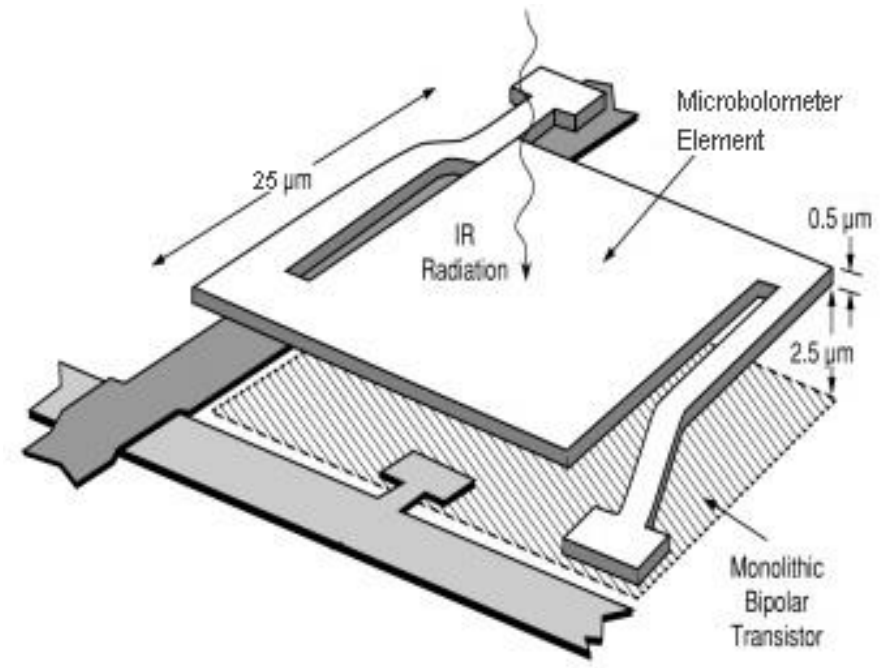

Fig. 4. Microbolometer detector [4]

\subsection{Basic parameters of thermal imaging cameras}

Manufacturers of thermovision cameras in the specifications of their products give many parameters, including the spectral range of the camera, the type and size of detectors, types of lenses, power consumption or weight and dimensions of the camera. However, the most important parameters are the temperature difference equivalent to noise (NETD), spatial resolution, and the 
minimum detectable temperature difference (MDTD) and the minimum diffuse temperature difference (MRTD). The resolution of the camera, i.e. the smallest detectable temperature difference, is determined by the MDTD (Minimum Detectable Temperature Difference) parameter. However, noise may occur during measurements. Temperature diffusion above their level is referred to as MRTD (Minimum Resolvable Temperature Difference). MRTD is also often called temperature sensitivity. This parameter takes into account the size of the object, the subjective characteristics of the camera operator and the type of monitor. In turn, NETD (Noise Equivalent Temperature Difference), called temperature resolution, does not consider these features. It is a parameter of the substitute resolution of the temperature of the noise signal, i.e. the difference of body temperature received by the detector and the background temperature causing the noise. When the noise is equal to the smallest measurable temperature difference, the detector achieves its thermal analysis signal limit. Therefore, the more noise there is in the signal, the higher the NETD value.

Typical uncooled cameras with bolometric detectors achieve NETD values of $45 \mathrm{mK}$, while scientific photon cameras with cooling systems can have a resolution of even $18 \mathrm{mK}$. The temperature resolution can be obtained from the formula:

$$
\mathrm{NETD}=\frac{U_{n}}{\Delta U / \Delta T}
$$

where:

Un - effective value of the noise voltage,

$\Delta \mathrm{U}$ - voltage increase of signals,

$\Delta T$ - increase in temperature difference between the object and the background.

Spatial resolution of cameras is defined by two parameters: elementary field of view of a single detector (IFOV - Instantaneous Field of View) and field of view of a thermal imaging camera (FOV Field of View). The detector's field of view can be described by equation (4).

$$
\mathrm{IFOV}=2 \operatorname{arctg} \frac{D}{2 d}=2 \operatorname{arctg} \frac{D_{d e t}}{2 \mathrm{f}}[\mathrm{rad}]
$$

Ddet - detector size,

$d$ - distance of the camera from the observed object,

$f$ - focal length of the lens.

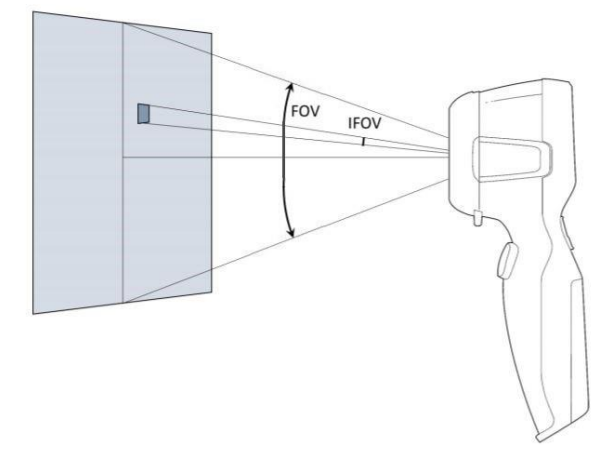

Fig. 5. Field of view of the camera FOV and IFOV detector

\subsection{Methodology of thermographic research}

Thermographic tests used in medicine are burdened with detailed standards defined by thermographic associations. These guidelines are not necessary to perform objective and correctly interpreted measurement results. The first guideline concerns the selection of a thermal imaging camera according to its infrared range. Considering the wavelength for which the skin reaches its 
maximum emittance $(9.36 \mu \mathrm{m})$, medium and far-infrared cameras can be qualified for thermographic studies. However, cameras with a medium range $(3-6 \mu \mathrm{m})$ will require a better adaptation of the room in which the examination is carried out due to greater sensitivity to solar radiation. It is also important to choose the appropriate focal length of the used camera. Depending on the distance from the observed object, you should choose a short focal length (if the observation is from a short distance) or longer (when the object is away from the researcher). In medicine, cameras with variable focal length (so-called zoom) have found the greatest application. The following guidelines describe the room in which thermographic measurements are to take place. The basic requirements for the room are sufficient space for convenient placement of measuring devices and comfortable use by the researcher and the respondent. It is assumed that the measuring room cannot be less than $6 \mathrm{~m}^{2}$, and the room with a minimum size of $3 \times 4 \mathrm{~m}$ is considered optimal. The room should also have appropriate conditions.

The most important here is maintaining a constant temperature in the range of $20-24^{\circ} \mathrm{C}$, and a constant relative air humidity of $45-55 \%$. Maintaining a constant value of both of these parameters prevents excessive heat exchange between the body and the environment, and thus unnatural warming or cooling of the body. In order to achieve this effect, one should also remember to limit the airflow, because increased circulation can affect the uneven temperature distribution.

In addition to the selection of equipment and the preparation of the test room, it is also necessary to ensure that the examined person is properly prepared. Guidelines on the conditions of conducting medical thermographic measurements require that the patient fill out a questionnaire prepared by the examiner. On its basis, the researcher catches contraindications for the thermographic measurement and possibly exclude such a person from the research group. Those patients who will be qualified for the study must be familiarized with all stages of the study and give their consent in writing.

The main contraindication to the qualification of a given patient for thermovision measurement is obesity and strong hair. The correct assessment of the measurement results in people suffering from obesity prevents the folds of fat and other symptoms of this disease, e.g. excessive sweating. Further disqualifying factors are dermatological changes, fresh tattoos or scars, unless they are the subject of the study.

Before starting thermographic measurements, the subject must acclimatize to the ambient conditions. Depending on the temperature difference between the test room and the place from which the subject came, the acclimatization should last from 15 to even 60 minutes. In the case when the aforementioned temperature difference is small acclimatization, it should last an average of 20 minutes, while with its increase the acclimatization time is longer. In acclimatization, the examined body surface should be discovered. This will ensure stabilization of heat transfer. When testing body temperature at rest, it is forbidden to touch, massage and lean against the area of the body being examined. Before thermographic examination, the patient should not consume warm drinks or meals, drink alcohol, smoke cigarettes and use drugs or medicines that could change the body temperature. In addition, it is required that no cosmetics are applied to the examined skin surface. The patient should also limit physical exercise and physiotherapeutic procedures, unless their impact on body temperature is the subject of the study.

\section{Research}

\subsection{Measuring equipment}

A ThermoCamera Compact Plus thermal imaging camera from Laserliner was used for the study (Figure 6). It is a small (weighing $0,5 \mathrm{~kg}$ ) thermal imaging camera equipped with an uncooled 
microbolometer detector operating in the $8-14 \mu \mathrm{m}$ range. All parameters of the thermal imaging camera shown table 1.

Tab. 1. Parameters of the thermal imaging camera

\begin{tabular}{|l|l|}
\hline \multicolumn{1}{|c|}{ Parameter } & \multicolumn{1}{c|}{ Value } \\
\hline Resolution & $80 \times 80$ pixels \\
\hline Optical system & Infrared lens made of germanium \\
\hline Picture function & Digital zoom 1-32x \\
\hline FOV field of view & $17^{\circ} \times 17^{\circ}$ \\
\hline Spatial resolution IFOV & 3,78 mrad \\
\hline Focal length & Adjustable in the range from $0,5 \mathrm{~m}$ to $10 \mathrm{~m}$ \\
\hline Thermal sensitivity NETD & $0,1^{\circ} \mathrm{C}$ \\
\hline Measurement range & $-20^{\circ} \mathrm{C}-150^{\circ} \mathrm{C}, 0^{\circ} \mathrm{C}-350^{\circ} \mathrm{C}$ \\
\hline Precision & $\pm 2^{\circ} \mathrm{C}$ lub $2 \%$ of the measured value \\
\hline
\end{tabular}

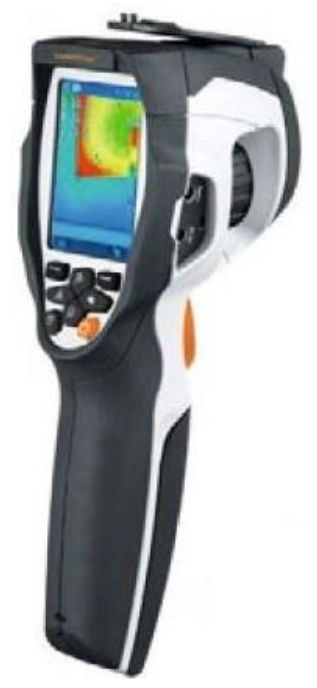

Fig. 6. Thermal imaging camera ThermoCamera Compact Plus from Laserliner

Tested athletes practiced on the Concept2 rowing ergometer version $\mathrm{E}$

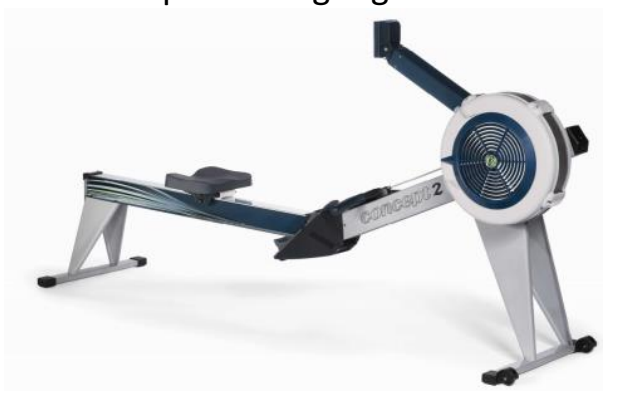

Fig. 7. Rowing ergometer Concept2 ver. E

\subsection{Research group}

The research involved a group of ten athletes actively training in the rowing ergometer section of the Academic Sports Association of the Lublin University of Technology. Table 2 contains collective 
characteristics of tested female athletes including data such as age and anthropometric weight, height, waist circumference and hips. These data allowed to assess the physique of female players using such markers as BMI (Body Mass Index) [5], BAI (Body Adiposity Index) and based on the percentage of adipose tissue. The percentage of adipose tissue was determined using the YMCA method.

Tab. 2. The characteristics of the players

\begin{tabular}{|c|c|c|c|c|c|c|c|}
\hline Player & Sex & Age & $\begin{array}{c}\text { Body } \\
\text { weight } \\
{[\mathrm{kg}]}\end{array}$ & $\begin{array}{c}\text { Growth } \\
{[\mathrm{cm}]}\end{array}$ & Waist [cm] & Loins [cm] & BMI \\
\hline 1 & W & 20 & 70 & 173 & 82 & 88 & 23,4 \\
\hline 2 & W & 21 & 55 & 162 & 72 & 82 & 21,0 \\
\hline 3 & W & 18 & 76 & 178 & 77 & 94 & 24,0 \\
\hline 4 & W & 23 & 68 & 185 & 75 & 86 & 19,9 \\
\hline 5 & W & 22 & 65 & 180 & 76 & 80 & 20,1 \\
\hline 6 & W & 21 & 68 & 171 & 78 & 91 & 23,3 \\
\hline 7 & W & 21 & 65 & 175 & 68 & 85 & 21,2 \\
\hline 8 & W & 20 & 63 & 175 & 72 & 97 & 20,6 \\
\hline 9 & W & 21 & 70 & 170 & 85 & 100 & 24,2 \\
\hline 10 & W & 20 & 56 & 164 & 73 & 94 & 20,8 \\
\hline Average & & 20,7 & 65,6 & 173,3 & 75,8 & 89,7 & 21,8 \\
\hline
\end{tabular}

Thermographic tests were carried out during the preparatory period and the players underwent endurance training. A single training unit lasted about 90 minutes and thermographic images taken before the start of training and immediately after its completion. At each competitor, three photos were taken in one series. They included the front and back surfaces of the arms and abdomen. The tests were carried out in accordance with current standards. Photographs were taken in a room with a total area of $140 \mathrm{~m} 2$ in $220 \mathrm{C}$ conditions and $50 \%$ air humidity. Emissivity of the skin at 0.98 was also accepted.

\subsection{Results}

Thermographic photos were taken in two series, before and after ergo metric training. Each of the thermograms focused on one of the three areas of the body: the front part of the arm, the back of the arm and the abdomen. The obtained thermograms were developed in the LaserLiner QucikReporting Editor environment. Due to the initially high difference in background, temperatures and the warmest body parts of the female players (difference of even $15^{\circ} \mathrm{C}$ ), a scale of colors from $25^{\circ} \mathrm{C}$ to the maximum temperature was adopted. This was justified by the need to increase the resolution/sensitivity of the temperature difference. The points of maximum and minimum temperatures were marked, which allowed comparative analysis both in terms of surface temperature distribution and in terms of its value. At work, the results of the measurements will be presented on the example of only one athlete.

Skater $\mathrm{nr} 1$ - woman aged 20, $173 \mathrm{~cm}$ tall $70 \mathrm{~kg}$ body weight, BMI 23.4 


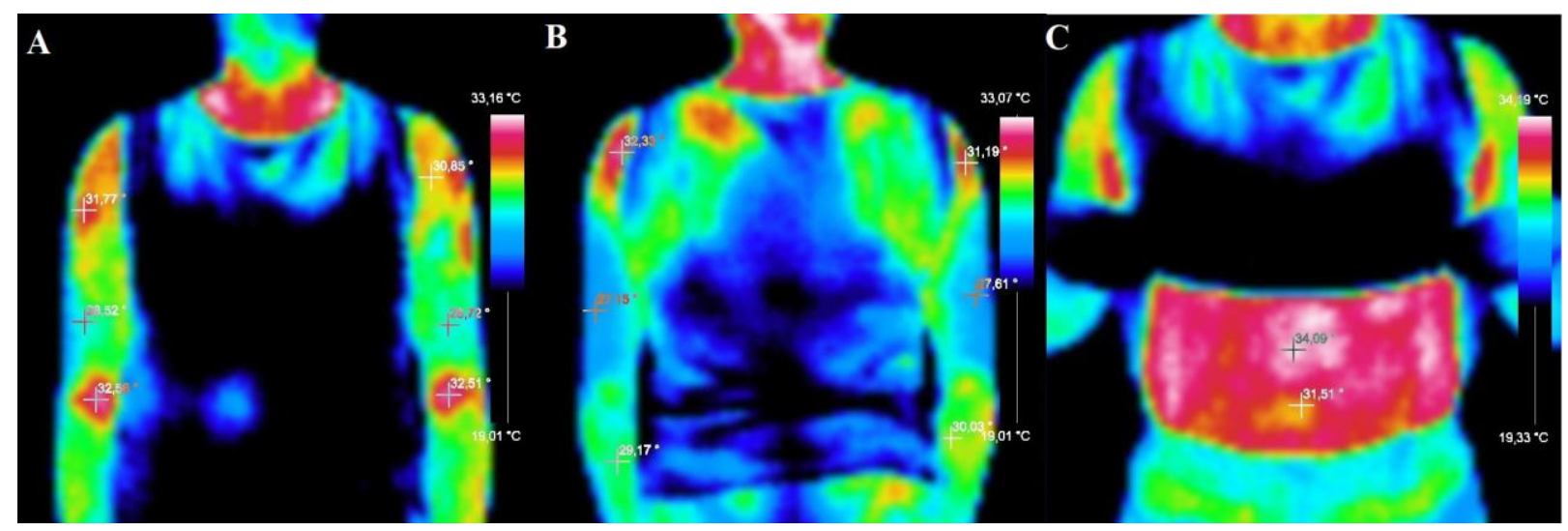

Fig. 8. Thermographs obtained before ergometric training on the front of the arms (A), back of the arms (B) and on the abdomen (C)

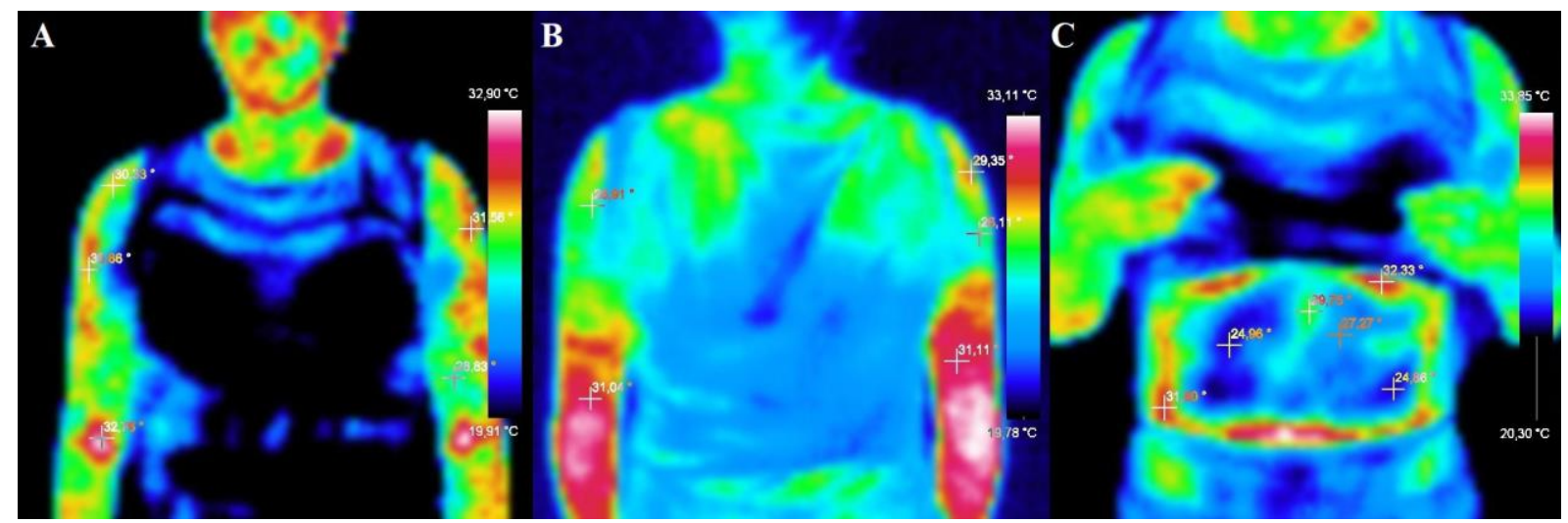

Fig. 8. Thermographs obtained after ergometric training on the front of the arms (A), back of the arms (B) and on the abdomen (C)

Thermograms performed before and after training on the rowing ergometer show changes in temperatures in all areas studied (Table 3). Temperatures recorded on the abdomen and shoulders of the athlete can provide important information about the training she has done.

Tab. 3. Differences in temperatures in the studied areas

\begin{tabular}{|l|l|l|l|c|c|c|c|c|c|c|}
\hline & \multicolumn{2}{|c|}{$\begin{array}{c}\text { Arms } \\
\text { Right front }\end{array}$} & \multicolumn{2}{c|}{$\begin{array}{c}\text { Arms } \\
\text { Left front }\end{array}$} & \multicolumn{2}{c|}{$\begin{array}{c}\text { Arms } \\
\text { Right back }\end{array}$} & \multicolumn{2}{c|}{$\begin{array}{c}\text { Arms } \\
\text { Left back }\end{array}$} & \multicolumn{2}{c|}{ Abdomen } \\
\hline & Before & After & Before & After & Before & After & Before & After & before & After \\
\hline $\begin{array}{l}\text { Temp. } \\
\text { Max }\end{array}$ & 31,77 & 30,66 & 30,85 & 31,56 & 31,19 & 31,11 & 32,33 & 31,04 & 34,09 & 32,33 \\
\hline $\begin{array}{l}\text { Temp. } \\
\text { Min. }\end{array}$ & 28,52 & 30,33 & 28,72 & 28,83 & 27,63 & 26,11 & 27,15 & 26,91 & 31,51 & 24,86 \\
\hline $\begin{array}{l}\text { Temp. } \\
\text { Aver. }\end{array}$ & 30,15 & 30,5 & 29,79 & 30,20 & 29,41 & 28,61 & 29,74 & 28,98 & 32,8 & 28,60 \\
\hline
\end{tabular}

Thermograms performed before and after training on the rowing ergometer show changes in temperatures in all areas studied. Temperatures recorded on the abdomen and shoulders of the athlete can provide important information about the training they have done.

A series of measurements made before the test showed an even temperature distribution on the front and back of the arms. Maximum temperatures were in the upper part of the arms, which 
could have been caused by the earlier covering of this surface with the sleeve of the clothes. The lower arms were at about $29^{\circ} \mathrm{C}$ on the front side and $27^{\circ} \mathrm{C}$ on the backside.

Thermographic images of the front surface of the legs indicate an increase in the average temperature after exercise and its uniform distribution. This suggests proper involvement of the biceps muscles. However, in the pictures taken from the back, there is a clear disproportion in the temperature distribution, especially in the areas of the triceps muscles of the arm. It is also worth paying attention to the large increase in the temperature of the forearms, especially their back parts.

In the pictures, depicting the abdomen before training athletes is visible high temperature $\left(34^{\circ} \mathrm{C}\right)$ spread over the entire surface of the test area. However, after the training you can observe a drop in temperature and inhomogeneous arrangement. The maximum temperature (around $32^{\circ} \mathrm{C}$ ) is visible around the hips, while its drop (around $25^{\circ} \mathrm{C}$ ) you can observed in the central part of the abdomen.

Disproportion noticed in the central part of the abdomen you can explained by the accumulation of fat in the belly button. The percentage of adipose tissue indicator showed overweight athletes. Although it has been qualified for this group at the lower limit, the effect of isolating adipose tissue on the measurement result should be taken into account.

Knowing the technique of exercising on the rowing ergometer and the muscle exercises involved in the subsequent stages, you can roughly indicate the athlete's mistakes. Disproportions in the temperature of biceps and triceps suggest a mistake during the first phase - the grip. A high temperature on the hips, however, indicates a large involvement of abdominal oblique muscles, but its decrease observed with the abdominal muscles means an error during the final phase of the exercise. Summing up, for the analyzed female athlete it is suggested to improve the technique of exercises during the first and third phase of the exercise.

\section{Summary and Conclusions}

Studies made of the temperature distribution of the body during the training on the rowing ergometer focused on three selected areas: the front and rear surfaces of the arms and abdomen.

The analyzed areas corresponded to the muscles of the successive two-headed arm, threeheaded arm and oblique muscles as well as straight abdominal muscles. The results of the conducted research confirmed the thesis that thermography is an appropriate tool supporting sports training, and in this case - on a rowing ergometer.

Testing with a thermal camera is a quick and completely safe method of assessing the temperature of the human body and the results obtained are easy to analyze [6] [7]. The material collected during the tests gives the possibility of both qualitative and quantitative analysis of the temperature of the studied areas. For people who know human anatomy it is also simple to indicate specific muscle parts for which the local temperature deviates from the norm.

During the tests of ten female athletes after training on the rowing ergometer, the expected temperature changes on the arms and abdomen were noticed. The involved muscles of biceps and triceps as well as oblique and abdominal muscles were confirmed to a different degree in each player. The variety of results obtained and their individual analysis for each of the surveyed women allowed to make conclusions about the technique of their exercises. The performed thermographic tests also confirmed the knowledge contained in the literature regarding the resting temperature of the studied areas [5] and contraindications to the study [6]. The main factor preventing the thermovision camera from being tested is the presence of adipose tissue. 


\section{References}

[1] "Hypothalamus | The Science of Psychotherapy." [Online]. Available: https://www.thescienceofpsychotherapy.com/glossary/hypothalamus/. [Accessed: 10-Jul-2019].

[2] "The three layers of your skin | Skin Institute." [Online]. Available: https://www.skininstitute.co.nz/dermatology/three-layers-skin/. [Accessed: 10-Jul-2019].

[3] J. Steketee, "Spectral emissivity of skin and pericardium - IOPscience." [Online]. Available: https://iopscience.iop.org/article/10.1088/0031-9155/18/5/307. [Accessed: 10-Jul-2019].

[4] "Microbolometer Detector." [Online]. Available: https://www.optotherm.com/microbolometers.htm. [Accessed: 10-Jul-2019].

[5] R. N. Bergman, D. Stefanovski, and T. A. Buchanan, "A Better Index of Body Adiposity," Obesity, vol. 19, no. 5, pp. 1083-1089, 2011.

[6] M. Chudecka and A. Lubkowska, "Termowizyjna ocena zmian temperatury powierzchni ciała koszykarzy po treningu, Acta Bio-Opt. Inform. Medica, vol. 17, no. 4, pp. 271-274, 2011.

[7] M. Chudecka, A. Lubkowska, and A. Kempińska-Podhorodecka, "Termowizyjna ocena zmian temperatury na powierzchni kończyn górnych u zawodników uprawiających waterpolo, Acta BioOpt. Inform. Medica, vol. 16, no. 4, pp. 334-338, 2010. 